\title{
Molecular basis of active copper resistance mechanisms in Gram-negative bacteria
}

\author{
Kinga Bondarczuk • Zofia Piotrowska-Seget
}

Received: 8 May 2013 /Accepted: 16 September 2013 / Published online: 27 September 2013

(C) The Author(s) 2013. This article is published with open access at Springerlink.com

\begin{abstract}
Copper is a metallic element that is crucial for cell metabolism; however, in extended concentrations, it is toxic for all living organisms. The dual nature of copper has forced organisms, including bacteria, to keep a tight hold on cellular copper content. This challenge has led to the evolution of complex mechanisms that on one hand enable them to deliver the essential element and on the other to protect cells against its toxicity. Such mechanisms have been found in both eukaryotic and prokaryotic cells. In bacteria a number of different systems such as extra- and intracellular sequestration, enzymatic detoxification, and metal removal from the cell enabling them to survive in the presence of high concentration of copper have been identified. Gram-negative bacteria, due to their additional compartment, need to deal with both cytoplasmic and periplasmic copper. Therefore, these bacteria have evolved intricate and precisely regulated systems which interact with each other. In this review the active mechanisms of copper resistance at their molecular level are discussed.
\end{abstract}

Keywords CopA $\cdot$ Copper resistance $\cdot \mathrm{Cu}^{+}$-ATPase . cue $\cdot$ CueP $\cdot c u s \cdot$ Multicopper oxidase $\cdot p c o \cdot$ RND

K. Bondarczuk $(\triangle) \cdot$ Z. Piotrowska-Seget Department of Microbiology, Faculty of Biology and Environment Protection, University of Silesia, Jagiellońska 28, 40-032 Katowice, Poland e-mail:kkrysta@us.edu.pl

\section{Introduction}

Transition metal copper is an essential trace element for all organisms living under aerobic conditions (Lee et al. 2002). It is required in fundamental cellular processes such as oxidative phosphorylation, photosynthesis, and free radical control. Copper atoms were found to be incorporated into periplasmic and inner membrane cuproproteins, e.g., $\mathrm{Cu}, \mathrm{Zn}$-superoxide dismutases, cytochrome c oxidase, and multicopper oxidases (Bannister and Bannister 1987; De la Cerda et al. 1997; Iwata 1998; Nakamura and Go 2005). In nature copper exists as a strong soft metal $\left(\mathrm{Cu}^{+}\right)$or is borderline $\left(\mathrm{Cu}^{2+}\right)$. This is the reason why amino acids containing soft (sulfur donor atoms) or borderline (nitrogen donor atoms) ligands predominate in copper-binding sites. They are represented by cysteine, methionine, or histidine, respectively. Proteins utilizing copper as a cofactor exhibit positive reduction potentials and are involved in electron transfer, oxygen transport as well as in redox reactions of multiple substrates (Dupont et al. 2011).

Despite the fact that copper plays an essential role in biological processes, it is highly toxic in excess. Macomber and Imlay (2009) have shown that copper degrades iron-sulfur clusters of dehydratases through iron displacement, causing inactivation of these crucial enzymes. Furthermore, iron released from the mentioned clusters may subsequently initiate the Fenton reaction that leads to oxidative damage inside the cell (Macomber and Imlay 2009).

Owing to its poisonous properties, copper has been utilized in medicine as well as in agriculture. It is a 
component of antibacterial agents, algaecides, and pesticides (Loftin et al. 2005). Copper additives are also present in animal feeds due to their growth stimulation value. Widespread use of copper-containing products has led to prolonged exposure of bacterial cells to copper. This, in consequence, has led to the selection of copper-resistant/tolerant strains. The best known copper-resistant bacteria were isolated from plant-, animal-, and human-associated bacteria.

\section{Mechanisms involved in copper homeostasis in bacteria}

The dual nature of copper poses a real challenge for living organisms. They need to engage multiple complex systems to strictly control cellular copper concentration (Fig. 1). Copper homeostasis requires a delicate balance between providing essential nutrients and preventing lethal excess (Puig et al. 2002). A number of processes such as intra- and extracellular sequestration, enzymatic detoxification, and active efflux were identified to maintain this balance in bacterial cells. Extracellular sequestration is possible due to the production of exopolysaccharides. These compounds bind copper ions by virtue of electrostatic interactions and keep them trapped outside the cell (González et al. 2010). Although the mentioned mechanisms appear to be a passive and nonspecific process, they can effectively protect bacteria against heavy metal toxicity. The other mechanisms specifically recognize copper and can probably distinguish between $\mathrm{Cu}$ (I) and $\mathrm{Cu}$ (II) as well. This review is devoted to the latter mechanisms which constitute a specific response to increasing copper concentration. The best studied copper-responsive systems in Gram-negative bacteria are cue, cus, pco, and cop from Escherichia coli and Pseudomonas syringae pv. tomato, respectively.

\section{Cue system-primary copper resistance system in $E$. coli}

Two chromosomally encoded systems named cue and $c u s$, involved in copper resistance, were identified in $E$. coli. The cue (for Cu efflux) system was found to be the main mechanism responsible for copper resistance in $E$. coli under both aerobic and anaerobic conditions (Outten et al. 2001; Rensing and Grass 2003). This system contains CueR - a copper-responsive metalloregulatory

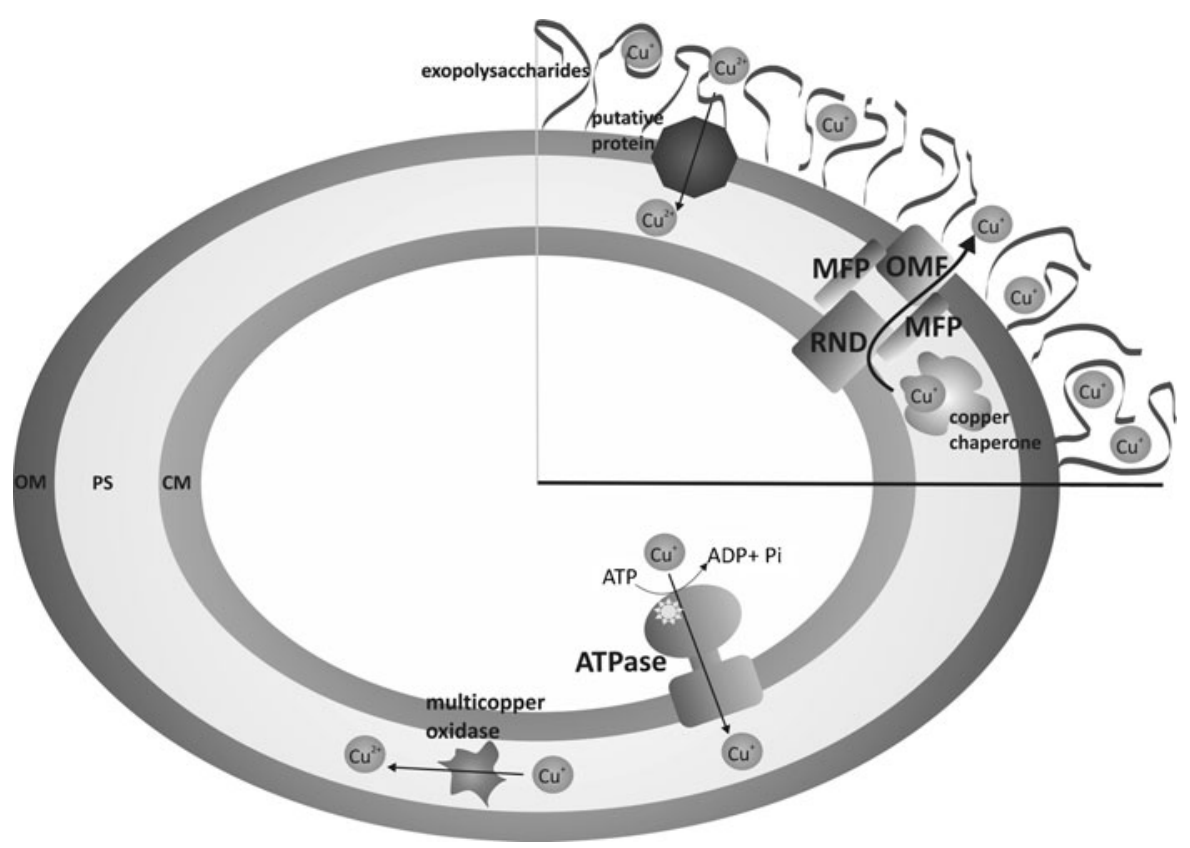

Fig. 1 Proteins involved in copper resistance in bacteria. Abbreviations: $C M$ cytoplasmic membrane, $P S$ periplasmic space, $O M$ outer membrane. Assignment of particular proteins: multicopper oxidase (CueO), RND (CusA), MFP (CusB), OMF (CusC), copper chaperone (CusF), ATPase (CopA) 
protein that is a homologue of MerR. It has been shown that CueR regulates the expression of two genes: cueO and copA (Grass and Rensing 2001; Outten et al. 2001).

The expression of the latter gene is induced by copper as well as silver ions (Rensing et al. 2000). The protein CopA contains 834 residues and belongs to the subfamily of soft metal ion-translocating ATPases. It has been demonstrated that CopA transports monovalent $\mathrm{Cu}$ from the cytoplasm, and the Cys-Pro-Cys motif (CPC) is essential in this process (Fan and Rosen 2002). In $\mathrm{Cu}^{+}$-ATPases subgroup, transport of $\mathrm{Cu}$ is coupled to ATP hydrolysis (Raimunda et al. 2011). On the basis of hydropathy analysis of CopA, eight transmembrane (TM) segments can be distinguished. In the predicted model $\mathrm{N}$-terminal region of CopA contains two cytoplasmic CXXC metalbinding domains. The phosphatase domain is located between TM4 and TM5. The other three domains, e.g., ATP binding, phosphorylation, and nucleotide binding domains are situated in a large intracellular loop between TM6 and TM7 (Rensing et al. 2000). So far, the crystal structure of this protein has not been solved. However, a crystal structure of another $\mathrm{Cu}^{+}$-ATPase, LpCopA, isolated from Legionella pneumophila has been described. It shares $45 \%$ amino acid sequence identity with CopA from E. coli and restores copper resistance in $\triangle$ copA mutant of this bacterium (Kim et al. 2009). The TM portion of the protein (M-domain) is formed by eight helices (M1-M6, MA and MB). Within the M-domain, Gourdon et al. (2011) described a novel structure named as "platform." It is formed by a kink in the second TM helix at the border of the membrane inner leaflet. The platform may constitute the docking site for copper delivery and/or LpCopA autoregulation by the metal-binding domain. The two membrane copper-binding sites (I and II) which are responsible for copper translocation were found in the M-domain (Gourdon et al. 2011). Gourdon et al. (2011) proposed a three-step model for copper transport mediated by LpCopA. According to this model, $\mathrm{Cu}^{+}$is delivered to the platform entry site (Met148, Glu205, and Asp337) and subsequently transferred to site II in the membrane during the E2 to E1 transition. Occluded, high-affinity copper-binding sites I and II may be formed by simultaneous rotational shift of M4 and conformational change at the CPC motif. The release of copper from binding sites is due to dephosphorylation process, which deprives the binding site of a crucial residue (Cys382). Copper ion may be then guided through an extracellular exit site (Gourdon et al. 2011; Robinson 2011). Positively charged residues localized around the putative entry site enable electrostatic interactions with a potential copper donor. It remains elusive whether the copper donor is a chaperone, the metal-binding domain itself, or both.

The second component of the cue system is $\mathrm{CueO}$, a periplasmic multicopper oxidase. This enzyme oxidizes $\mathrm{Cu}$ (I) to a less toxic $\mathrm{Cu}$ (II) and reduces dioxygen to water through four single-electron transfer steps (Djoko et al. 2010; Outten et al. 2001; Roberts et al. 2002). Multicopper oxidases possess three types of copper atoms: type 1 (T1), type 2 (T2), and two type 3 (T3). The T1 site is buried in the interior of the protein and generally catalyzes oxidation of the substrate while $\mathrm{T} 2$ and two T3 form a trinuclear center (TNC) where dioxygen is reduced. The CueO activity is oxygen dependent, and hence, the lack of these molecules terminates the reaction (Outten et al. 2001; Singh et al. 2011). $\mathrm{CueO}$ differs from other multicopper oxidases due to its notable feature, i.e., an extra methionine-rich helix that blocks the solvent access to the $\mathrm{T} 1$ site and forms an additional copper-binding site (Singh et al. 2004, 2011). A similar methionine-rich region was also identified in PcoA in E. coli and CopA in P. syringae (Roberts et al. 2002).

\section{Cus system}

While CopA extrudes the excess copper from the cytoplasm, CueO and cus system (CusCFBA) are involved in periplasmic copper detoxification. Presumably, oxygen limitation may prevent the activity of the multicopper oxidase. In this case periplasmic copper can be removed by CusCFBA (Outten et al. 2001). Since silver ions inhibit $\mathrm{CueO}$ activity, it has been also suggested that the cus system may function to overcome $\mathrm{Ag}(\mathrm{I})$ poisoning of the cue system under aerobic conditions (Singh et al. 2011).

CusCFBA was found in $E$. coli and, unlike the other CBA-type efflux mechanisms, is a tetrapartite system conferring resistance to copper and silver ions (Grass and Rensing 2001; Franke et al. 2001, 2003). CBAtype pumps comprise proteins belonging to three distinct groups: inner membrane secondary transporters enabling proton-driven substrate translocation from the cytoplasm (resistance-nodulation-cell division superfamily, RND), outer membrane channels exporting substrate outside the cell (outer membrane factor 
family, OMF), and finally, periplasmic membrane fusion proteins (membrane fusion proteins family, MFP) connecting the two components mentioned above (Kim et al. 2010).

The cus system contains four proteins: CusC, CusB, CusF, and CusA. While CusCBA constitutes a phenomenal efflux system spanning the entire cell envelope, CusF is a periplasmic chaperone required for full resistance. A member of the RND superfamily, CusA is a homotrimer consisting of 1,047 residues (Long et al. 2010). In a single monomer 12 transmembrane helices (TM1-TM12) form a transmembrane region in which pseudo-twofold symmetry was observed. The periplasmic domain is composed of two loops: one between TM1 and TM2 and another between TM7 and TM8. The periplasmic domain of CusA may be divided into six subdomains. Four subdomains (PN1, PN2, PC1, $\mathrm{PC} 2$ ) constitute the pore domain, DN and DC form the CusC-docking domain, and PN1 contributes to the central pore. Moreover, the presence of the cytoplasmic domain has also been confirmed. It is postulated that CusA is able to transport copper from the periplasm. In this stepwise process five methionine pairs or clusters serve as a relay network enabling metal translocation along the protein. In addition, subdomains PC1 and PC2 form a periplasmic cleft that is plausibly opened when bound with the metal and closed in the absence of the substrate (Long et al. 2010; Su et al. 2011b).

CusB is an elongated, adaptor molecule that belongs to the MFP Family. This protein consists of four distinct domains; the first three of them are $\beta$-strand domains. The fourth domain is an all-helical region folded into a three-helix bundle structure. Crystallographic studies revealed that CusB occurs in two different conformations. The observed flexibility can be connected with a hinge located between domains 2 and 3 . The presence of the hinge permits the switch from one conformational state to another (Bagai et al. 2007; Su et al. 2009).

The crystal structure of CusBA complex revealed that trimeric CusA interacts with six CusB proteins. Adaptor molecules are organized in a continuous funnel-like structure at the top of CusA which approaches the outer membrane. The interior of the channel is mostly negatively charged that is connected with cation binding. Therefore, CusB, apart from being an adaptor molecule, is also considered to play a role in the active export of $\mathrm{Cu}$. Su et al. (2011a) proposed that the N-terminal three-methionine binding site might be responsible for the transport of metal ions into the periplasmic cleft of CusA (Su et al. 2011a).

Moreover, the three-helix bundle of CusB presumably interacts with CusC. Trimeric CusC, a member of the OMF family, is anchored into the outer membrane by three acyl chains (Kulathila et al. 2011). It forms a $\sim 130$ - $\AA$-long outer membrane channel that is composed of a periplasmic $\alpha$-barrel, an outer membrane $\beta$-barrel, and an equatorial domain. The internal cavity of CusC is filled with water whereas the internal surface of the barrel exhibits an electronegative charge (Kulathila et al. 2011).

The fourth component of this tetrapartite system is a periplasmic metallochaperone CusF folded in a small barrel (Loftin et al. 2005). It interacts with CusB directly transmitting $\mathrm{Cu}$. CusF may play then a dual protective role by removing excess copper from the periplasm by sequestration and by delivering this metal to CusCBA, thus enhancing export. Another possible role of CUsF may be connected with the specific selection of metals to prevent their undesirable removal (Bagai et al. 2008; Loftin et al. 2005, 2009).

\section{The pco system and its homologues}

Some bacteria that are able to survive in copper-rich environments possess plasmid-encoded operons that confer resistance to this toxic compound. The pco (plasmid-borne copper resistance) system was found on conjugative plasmid pRJ1004 isolated from E. coli that resided in the gut of pigs fed a diet supplemented with copper sulfate. The $p c o$ gene cluster comprises seven genes $p c o A B C D R S E$ that are under control of two promoters induced by copper ions (Rouch and Brown 1997; Huffman et al. 2002). Introduction of the complete $p c o$ determinant to copper-sensitive $E$. coli $\triangle$ copA mutant did not improve the level of tolerance. Therefore, mutational analysis indicated a linkage between chromosomally encoded and plasmid-borne copper resistance. The pco system requires CopA activity to confer resistance. Presumably, proteins encoded in the pco gene cluster are responsible for the handling of periplasmic copper delivered by CopA from the cytoplasm (Lee et al. 2002).

PcoA is a multicopper oxidase distantly related to $\mathrm{CueO}$ but can function as a substitute for its homologue (Lee et al. 2002). It is composed of a seven-stranded antiparallel $\beta$ barrel with the methionine-rich segment 
exposed to the solvent. This periplasmic oxidase together with PcoC has been postulated to be the crucial proteins of the pco system. In the proposed model, PcoC binds periplasmic $\mathrm{Cu}(\mathrm{I})$ and delivers it to PcoA for further oxidation. Another possible role of PcoC may be the transport of electrons (Huffman et al. 2002; Wernimont et al. 2003). PcoB is predicted to be an outer membrane protein that potentially prevents copper uptake and may interact with PcoA (Lee et al. 2002; Rensing and Grass 2003). The function of PcoD is still unknown but may be connected with copper uptake across the inner membrane (Lee et al. 2002). The product of $p c o E$ does not have any detectable influence on copper resistance but is strongly induced by copper (Lee et al. 2002). Unlike other genes from the $p c o$ cluster, $p c o E$ is controlled by CusRS (Munson et al. 2000). Presumably, PcoE acts as a primary defense factor providing initial sequestration of periplasmic copper before complete induction of the pco system is achieved (Lee et al. 2002).

A homologous plasmid-borne copper resistance was found in a plant pathogen-P. syringae pathovar tomato (Silver 1996). The copper-inducible equivalent system is encoded by six genes copABCDRS localized within the plasmid pPT23D (Cha and Cooksey 1991). What is more, copper accumulation in $P$. syringae rises to a spectacular feature that may be seen by the naked eye. That is, upon exposure to a high concentration of copper, cells become blue and accumulate $\mathrm{Cu}$ up to $12 \%$ of their dry weight (Puig et al. 2002). The periplasmic CopA shares homology with multicopper oxidases and contains methionine, histidine, and aspartic acid-rich motifs that enable it to bind up to 11 copper ions (Cha and Cooksey 1991; Cooksey 1993). Therefore, multicopper oxidase activity as well as high copper-binding capacity or both these properties of CopA together may play a role in copper resistance. CopB also contains many methionine residues; however, copper-binding abilities of this outer membrane protein have not been proven so far (Arnesano et al. 2002; Puig et al. 2002; Zhang et al. 2006). CopC is a soluble periplasmic chaperone folded into a Greek key $\beta$ barrel. It comprises two distinct but interdependent binding sites with specific affinity for $\mathrm{Cu}$ (I) and $\mathrm{Cu}$ (II), respectively. It has been proposed that this protein may be a copper carrier that interacts with multiple partners due to flexibility of the two Cu-binding loops. In the proposed model (Fig. 2), CopC can potentially interact with CopA, CopB, CopD, and CopS-a sensor protein
(Zhang et al. 2006). Eight transmembrane segments embed CopD in the plasma membrane. Mutational analysis indicated that both CopC and CopD are responsible for copper accumulation in the cytoplasm; thus, CopD may transport essential copper delivered by CopC through the inner membrane into the cytoplasm (Cooksey 1993; Arnesano et al. 2002). T2 copper site and residues in the methionine-rich loop observed in CopC may provide a dual function of this protein. While the T2 copper site may be involved in interactions with CopD to import essential copper, the other sites may enable interactions with CopA and/or CopB to detoxify excess copper (Arnesano et al. 2002). CopS and CopR form a two-component regulatory module that is constitutively transcribed. CopS is predicted to be a copper sensor that presumably interacts with CopA or CopC. This membrane sensor potentially transmits the copper signal to CopR which consecutively induces the expression of the cop operon (Puig et al. 2002).

Genes homomogous to cop were identified on plasmids and chromosomes of other Pseudomonads. It has been suggested that the plasmid-encoded cop operon evolved from its chromosomal homologue (Cooksey et al. 1990). Unusually in Pseudomonas fluorescens SBW25 operon cop consists of only two genes copCD and is regulated by the CopRS two-component system. In this bacterium, CopCD together with Cue system are involved in copper homeostasis. The first is active at low-copper concentration in the environment and brings metal ions into the cell, whereas the second acts as a copper exporter at high copper concentrations. The copper efflux is mediated by P-type ATPase CueA which is regulated by the Mer-type regulator, CueR. This protein is also required for activation of cueZ encoding copper chaperone. Due to the common regulation of cueZ and cueA by CueR, it has been thought that CueZ transfers copper to CueA. However, the higher resistance of bacterium deprived from cueZ suggested that the primary role of this chaperone is the delivery of copper ions to cellular cuproenzymes (Zhang and Rainey 2008).

The cop system was also found in heavy metalresistant Cupriavidus metallidurans $\mathrm{CH} 34$. Two gene clusters copSRABCD and a larger one copVTMKNSR $A B C D I J G F L Q H E$ that are highly induced by copper are localized on two large plasmids: $2,6 \mathrm{Mb}$ megaplasmid and pMOL30, respectively. The basic operon copSRABCD encodes genes which are homologous to the above-mentioned plasmid-borne cop/pco 


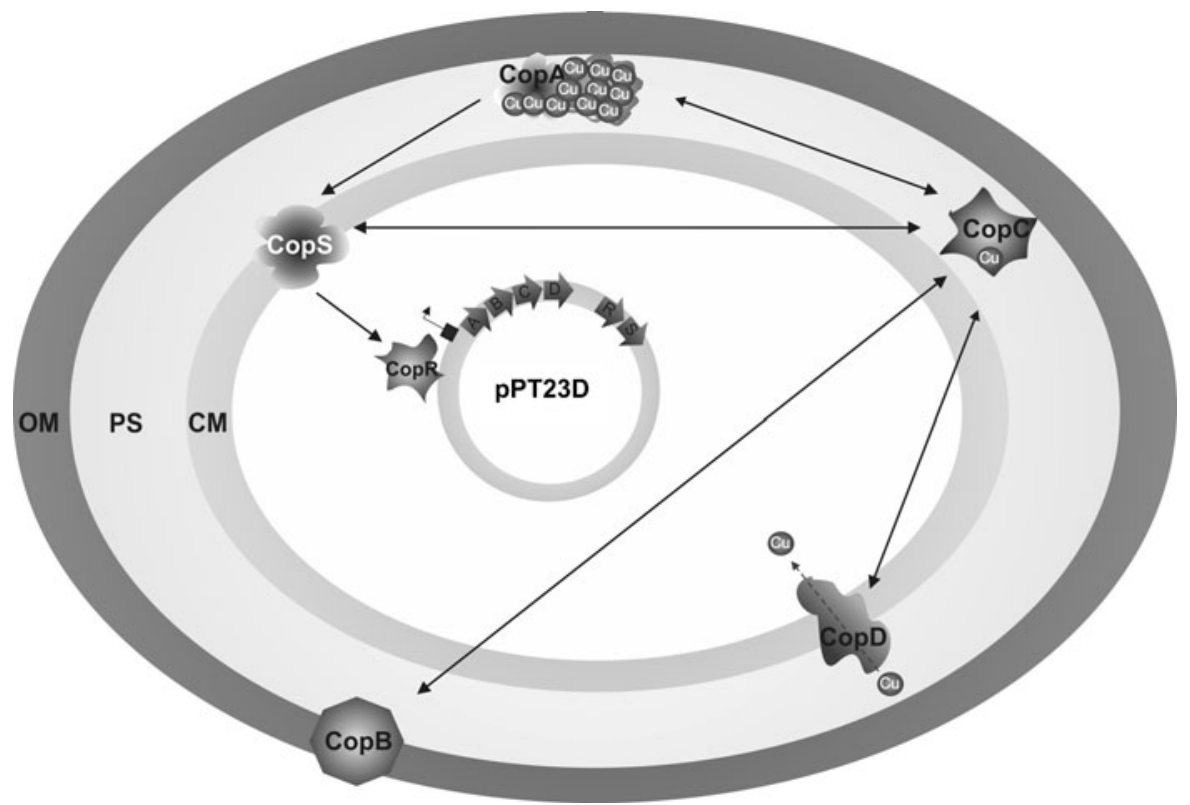

Fig. 2 A model for cop system in P. syringae pv. Tomato. Abbreviations: $C M$ cytoplasmic membrane, $P S$ periplasmic space, $O M$ outer membrane. Arrows indicate presumed interactions between proteins (modified from Puig et al. 2002)

systems (Monchy et al. 2006; Sarret et al. 2010). Monchy et al. (2006) qualified the genes into three groups, i.e., responsible for periplasmic or cytoplasmic copper handling and the third group of genes with few or no homologues (Monchy et al. 2006; Sarret et al. 2010).

It has been shown that the above-mentioned twocomponent regulatory system CopRS is present also in Synechocystis sp. PCC 6803. In this bacterium, CopRS regulates a RND export system, CopBAC, and a protein of unknown function CopM (Giner-Lamia et al. 2012). In addition, in Synechocystis, a metallochaperone Atx1 protects the cyanobacterial cell against the deleterious side reactions of copper (Tottey et al. 2012).

\section{Other systems involved in copper resistance}

Another copper resistance mechanism was found in the human and animal pathogen Salmonella enterica sv. Typhimurium. During a systemic disease, this bacterium can withstand elevated copper concentration within the macrophage phagosome and survive in this compartment (Osman et al. 2010). Like E. coli, S. enterica ser. Typhimurium harbors the cue system that allows it to deal with excess cytoplasmic copper under aerobic conditions. Interestingly, this bacterium evidently lacks the cus operon. Apart from multicopper oxidase
CueO (alias CuiD) and P-type ATPase CopA, the CueR up-regulates the expression of the additional protein-CueP. Furthermore, S. enterica possesses an extra P-type Cu-ATPase, GolT, encoded by the gol gene cluster, involved in gold resistance. Both P-type ATPases CopA and GolT were found to reduce copper accumulation in the cell probably by active export of copper from the cytoplasm. An additional component of the cue system, the $\mathrm{CueP}$ is a periplasmic protein that contributes to copper resistance particularly under anaerobic conditions. It is interesting to note that $\mathrm{CueP}$ can partially restore copper resistance in the E. coli $\Delta c u s$ mutant strain; thus, it may act as a substitute of the mentioned system. This protein binds periplasmic copper in vivo and was identified as one of the predominant metal pools (Osman et al. 2010). Moreover, the deletion of cueP slightly increases the copper content in the cell. Due to these characteristics, CueP binds elevated copper to avoid its toxicity in the periplasm and/or to limit the return of copper to the cytosol. CueP-like proteins are encoded in other Gram-negative bacteria, including Yersinia pestis, Yersinia pseudotuberculosis, Yersinia enterocolitica, Citrobacter koseri, and Erwinia carotovora (Osman et al. 2010; Pontel and Soncini 2009).

In another human pathogen, Vibrio cholerae, copper resistance mechanisms such as $\mathrm{CueP}$ as well as $\mathrm{CueO}$, 
CusCFBA were not detected. In this bacterium copper tolerance is determined by $\operatorname{cop} A$ (VC2215) and cueR (VC0974) (Marrero et al. 2012) that are homologous to genes copA and cueR found in E. coli (Grass and Rensing 2001). In V. cholerae, CopA is the main efflux system used under aerobic and anaerobic conditions that is regulated by CueR which senses copper inside the cell (Marrero et al. 2012). Apart from CopA, V. cholerae has a gene encoding for another $\mathrm{Cu}^{+}$-ATPase belonging to FixI/CopA2-like $\mathrm{Cu}^{+}$-ATPases (GonzálezGuerrero et al. 2010). In addition, Marrero et al. (2012) identified products of genes VC2216 and VCA02610260 that are required for full copper tolerance of $V$. cholerae. The proteins encoded by the mentioned genes are homologous to CopG recognized in Ralstonia metallidurans (Monchy et al. 2006) and Cot found in Pseudomonas fluorescens (Tom-Petersen et al. 2001), respectively. Bioinformatic analyses revealed that CopG and Cot are metal-binding periplasmic proteins; therefore, they may constitute a component of an alternative periplasmic copper tolerance system in $V$. cholerae (Marrero et al. 2012). CopG is a putative cupredoxin, and Cot is predicted to be a metal-binding protein belonging to the thioredoxin-like fold superfamily. It has been assumed that the function of CopG in the periplasmic space might be closely related to CopA. Like in the case of $\operatorname{cop} A$, the expression of $\cot$ is probably regulated by CueR (Marrero et al. 2012). Marrero et al. (2012) proposed a model for the copper tolerance mechanism in $V$. cholerae. The presence of copper activates the CueR regulator that induces the expression cop $A$ and cot. The transport of the excess copper from the cytoplasm by the CopA ATPase is correlated with the overexpression of Cot protein that would initially detoxify copper in the periplasm. Under anaerobic conditions, when the Cot protein loses its high activity, CopG protein takes over the main role in copper detoxification. The detailed mechanisms of copper handling by periplasmic proteins CopG and Cot have not been recognized yet (Marrero et al. 2012).

\section{Concluding remarks}

Most genomes of Gram-negative bacteria encode at least one $\mathrm{Cu}^{+}$-ATPase that is responsible for cytoplasmic copper detoxification. In addition, ATPases are required for bacterial survival in the host organism. That is why extra copies of $\mathrm{Cu}^{+}$-ATPases have been found in the genomes of pathogenic and symbiotic bacteria. For example, Pseudomonas aeruginosa, an opportunistic pathogen, possesses two homologous $\mathrm{Cu}^{+}$-ATPases CopA1 and Cop A2 (González-Guerrero et al. 2010). Although both proteins export cytoplasmic copper into the periplasm, their functional roles are different. The major role of CopA1 seems to be the control of cytoplasmic $\mathrm{Cu}^{+}$concentration, while CopA2 probably enables copper loading into cytochrome $\mathrm{c}$ oxidase. The distinct roles might be related to the intrinsic differences in transport kinetics and by the presence of putative periplasmic proteins acting as copper chaperons that deliver the ions to copper-requiring enzymes (GonzálezGuerrero et al. 2010).

ATPase-driven copper efflux seems to be the main mechanism responsible for cytoplasmic copper detoxification in until now studied bacteria. In periplasmic copper handling multicopper oxidases, metallochaperones, as well as RND systems are involved.

Open Access This article is distributed under the terms of the Creative Commons Attribution License which permits any use, distribution, and reproduction in any medium, provided the original author(s) and the source are credited.

\section{References}

Arnesano F, Banci L, Bertini I, Thompsett AR. Solution structure of CopC: a cupredoxin-like protein involved in copper homeostasis. Structure. 2002;10:1337-47.

Bagai I, Liu W, Rensing C, Blackburn NJ, McEvoy MM. Substrate-linked conformational change in the periplasmic component of $\mathrm{Cu}(\mathrm{I}) / \mathrm{Ag}$ (I) efflux system. J Biol Chem. 2007;282:35695-702.

Bagai I, Rensing C, Blackburn NJ, McEvoy MM. Direct metal transfer between periplasmic proteins identifies a bacterial copper chaperone. Biochemistry. 2008;47:11408-14.

Bannister JV, Bannister WH. Aspects of the structure, function, and applications of superoxide dismutase. CRC Crit Rev Biochem. 1987;22:111-90.

Cha JS, Cooksey DA. Copper resistance in Pseudomonas syringae mediated by periplasmic and outer membrane proteins. Microbiology. 1991;88:8915-9.

Cooksey DA. Copper uptake and resistance in bacteria. Mol Microbiol. 1993; 7:1-5.

Cooksey DA, Azad HR, Cha JR, Lim CK. Copper resistance gene homologs in pathogenic and saprophytic bacterial species from tomato. Appl Environ Microb. 1990;56:4315.

De la Cerda B, Navarro JA, Hervás M, De la Rosa M. Changes in the reaction mechanism of electron transfer from plastocyanin to photosystem I in the cyanobacterium Synechocystis sp. PCC 6803 as induced by site-directed mutagenesis of the copper protein. Biochemistry. 1997;36:10125-30. 
Djoko KY, Chong LX, Wedd AG, Xiao Z. Reaction mechanisms of the multicopper oxidase CueO from Escherichia coli support its functional role as a cuprous oxidase. J Am Chem Soc. 2010;132:2005-15.

Dupont CL, Grass G, Rensing C. Copper toxicity and the origin of bacterial resistance-new insights and applications. Metallomics. 2011;3:1109-18.

Fan B, Rosen BP. Biochemical characterization of CopA, the Escherichia coli $\mathrm{Cu}(\mathrm{I})$-translocating P-type ATP-ase. J Biol Chem. 2002;277:46987-92.

Franke S, Grass G, Dietrich HN. The product of the $y b d E$ gene of the Escherichia coli chromosome is involved in detoxification of silver ions. Microbiology. 2001;147:965-72.

Franke S, Grass G, Rensing C, Nies D. Molecular analysis of the copper-transporting efflux system CusCFBA of Escherichia coli. J Bacteriol. 2003;185:3804-12.

Giner-Lamia J, Maury-López L, Reyes JC, Florencio FJ. The CopRS two-component system is responsible for resistance to copper in the cyanobacterium Synechocystis sp. PCC 6803. Plant Physiol. 2012;159:1806-18.

González AG, Shirokova LS, Pokrovsky OS, Emnova EE, Martínez RE, Santana-Casiano JM, et al. Adsorption of copper on Pseudomonas aureofaciens: protective role of surface exopolysaccharides. J Colloid Interf Sci. 2010;350:305-14.

González-Guerrero M, Raimunda D, Cheng X, Argüello JM. Distinct functional roles of homologous $\mathrm{Cu}+$ efflux ATPases in Pseudomonas aeruginosa. Mol Microbiol. 2010;78:1246-58.

Gourdon P, Liu XY, Skjørringe T, Morth JP, Møller LB, Pedersen $\mathrm{BP}$, et al. Crystal structure of a cooper-transporting PIBtype ATPase. Nature. 2011;475:59-65.

Grass G, Rensing C. Genes involved in copper homeostasis in Escherichia coli. J Bacteriol. 2001;183:2145-7.

Huffman DL, Huyett J, Outten FW, Doan PE, Finney LA, Hoffman BM, et al. Spectroscopy of $\mathrm{Cu}(\mathrm{II})-\mathrm{PcoC}$ and the multicopper oxidase function of PcoA, two essential components of Escherichia coli pco copper resistance operon. Biochemistry. 2002;41:10046-55.

Iwata S. Structure and function of bacterial cytochrome c oxidase. J Biochem. 1998;123:369-75.

Kim EH, Charpentier X, Torres-Urquidy O, McEvoy MM, Rensing C. The metal efflux island of Legionella pneumophila is not required for survival in macrophages and amoebas. FEMS Microbiol Lett. 2009;301:164-70.

Kim HM, Xu Y, Lee M, Piao S, Sim SH, Ha NC, et al. Functional relationships between the AcrA hairpin tip region and the TolC aperture tip region for the formation of the bacterial tripartite efflux pump AcrAB-TolC. J Bacteriol. 2010;192:4498-503.

Kulathila R, Kulathila R, Indic M, Berg B. Crystal structure of Escherichia coli $\mathrm{CusC}$, the outer membrane component of a heavy metal efflux pump. PLOS One. 2011;6:1-7.

Lee SM, Grass G, Rensing C, Barrett SR, Yates CJD, Stoyanov JV, et al. The Pco proteins are involved in copper handling in Escherichia coli. Biochem Bioph Res Co. 2002;295:616-20.

Loftin IR, Franke S, Roberts SA, Weichsel A, Héroux A, Montfort WR, et al. A novel copper-binding fold for the periplasmic copper resistance protein CusF. Biochemistry. 2005;44:10533-40.

Loftin IR, Blackburn NJ, McEvoy MM. Tryptophan $\mathrm{Cu}(\mathrm{I})-\pi$ interaction fine-tunes the metal binding properties of the bacterial metallochaperone CusF. J Biol Inorg Chem. 2009;14:905-12.
Long F, Su CC, Zimmermann MT, Boyken SE, Rajashankar KR, Jernigan RL, et al. Crystal structures of the CusA efflux pump suggest methionine-mediated metal transport. Nature. 2010;467:484-90.

Macomber L, Imlay JA. The iron-sulfur clusters of dehydratases are primary intracellular targets of copper toxicity. PNAS. 2009;106:8344-9.

Marrero K, Sánchez A, González LJ, Ledón T, Rodríguez-Ulloa A, Castellanos-Serra L, et al. Periplasmic proteins encoded by VCA0261-0260 and VC2216 genes together with copA and cueR products are required for copper tolerance but not for virulence in Vibrio cholerae. Microbiology. 2012;158:2005-16.

Monchy S, Benotmane MA, Wattiez R, Aelst S, Auquier V, Borremans B, et al. Transcriptomic and proteomic analyses of the pMOL30-encoded copper resistance in Cupriavidus metallidurans strain CH34. Microbiology. 2006;152:1765-76.

Munson GP, Lam DL, Outten FW, O'Halloran TV. Identification of a copper-responsive two-component system on the chromosome of Escherichia coli K-12. J Bacteriol. 2000;182:5864-71.

Nakamura K, Go N. Function and molecular evolution of multicopper blue proteins. CMLS Cell Mol Life Sci. 2005;62:2050-66.

Outten FW, Huffman DL, Hale JA, O'Halloran TV. The independent cue and cus systems confer copper tolerance during aerobic and anaerobic growth in Escherichia coli. J Biol Chem. 2001;276:30670-7.

Osman D, Waldron KJ, Denton H, Taylor CM, Grant AJ, Mastroeni P, et al. Copper homeostasis in Salmonella is atypical and copper-CueP is a major periplasmic metal complex. J Biol Chem. 2010;285:25259-68.

Pontel LB, Soncini FC. Alternative periplasmic copperresistance mechanisms in Gram negative bacteria. Mol Microbiol. 2009;73:212-25.

Puig S, Rees EM, Thiele DJ. The ABCDs of periplasmic copper trafficking. Structure. 2002;10:1292-5.

Raimunda D, González-Guerrero M, Leeber BW, Argüello JM. The transport mechanism of bacterial $\mathrm{Cu}^{+}$-ATPases: distinct efflux rates adapted to different function. Biometals. 2011;24:467-75.

Rensing C, Fan B, Sharma R, Mitra B, Rosen BP. CopA: an Escherichia coli $\mathrm{Cu}(\mathrm{I})$-translocating P-type ATPase. PNAS. 2000;97:652-6.

Rensing C, Grass G. Escherichia coli mechanisms of copper homeostasis in a changing environment. FEMS Microbiol Rev. 2003;27:197-213.

Roberts SA, Weichsel A, Grass G, Thakali K, Hazzard JT, Tollin $\mathrm{G}$, et al. Crystal structure and electron transfer kinetics of $\mathrm{CueO}$, a multicopper oxidase required for copper homeostasis in Escherichia coli. PNAS. 2002;99:2766-71.

Robinson NJ. A platform for copper pumps. Nature. 2011;475:412.

Rouch DA, Brown NL. Copper-inducible transcriptional regulation at two promoters in the Escherichia coli copper resistance determinant pco. Microbiology. 1997;143:1191-202.

Sarret G, Favier A, Covès J, Hazzemann JL, Mergeay M, Bersch B. CopK from Cupriavidus metallidurans $\mathrm{CH} 34$ binds $\mathrm{Cu}(\mathrm{I})$ in a tetrathioether site: characterization by X-ray absorption and NMR spectroscopy. J Am Chem Soc. 2010;132:3770-7.

Silver S. Bacterial resistances to toxic metal ions - a review. Gene. 1996;179:9-19. 
Singh SK, Grass G, Rensing C, Montfort WR. Cuprous oxidase activity of CueO from Escherichia coli. J Bacteriol. 2004;186:7815-7.

Singh SK, Roberts SA, Franke McDevitt S, Weichsel A, Wildner GF, Grass GB, et al. Crystal structures of multicopper oxidase CueO bound to copper(I) and silver(I): functional role of a methionine-rich sequence. J Biol Chem. 2011;286:37849-57.

Su CC, Yang F, Long F, Reyon D, Routh MD, Kuo DW, et al. Crystal structure of the membrane fusion protein CusB from Escherichia coli. J Mol Biol. 2009;393:342-55.

Su CC, Long F, Zimmermann MT, Rajashankar KR, Jernigan RL, Yu EW. Crystal structure of the CusBA heavy-metal efflux complex of Escherichia coli. Nature. 2011a;470:558-63.

$\mathrm{Su} \mathrm{CC}$, Long F, Yu EW. The Cus efflux system removes toxic ions via a methionine shuttle. Protein Sci. 2011b;20:6-18.

Tom-Petersen A, Hosbond C, Nybroe O. Identification of copper-induced genes in Pseudomonas fluorescens and use of a reporter strain to monitor bioavailable copper in soil. FEMS Microbiol Ecol. 2001;38:59-67.

Tottey S, Patterson CJ, Banci L, Bertini I, Felli IC, Pavelkova A, et al. Cyanobacterial metallochaperone inhibits deleterious side reactions of copper. PNAS. 2012;109:95-100.

Wernimont AK, Huffman DL, Finney LA, Demeler B, O'Halloran TV, Rosenzweig AC. Crystal structure and dimerization equilibria of $\mathrm{PcoC}$, a methionine-rich copper resistance protein from Escherichia coli. J Biol Inorg Chem. 2003;8:185-94.

Zhang L, Koay M, Maher MJ, Xiao Z, Wedd AG. Intermolecular transfer of copper ions from the CopC protein of Pseudomonas syringae. Crystal structures of fully loaded $\mathrm{Cu}^{\mathrm{I}} \mathrm{Cu}^{\mathrm{II}}$ forms. J Am Chem Soc. 2006;128:5834-50.

Zhang XX, Rainey PB. Regulation of copper homeostasis in Pseudomonas fluorescens SBW25. Environ Microbiol. 2008;10:3284-94. 